\title{
EFEITOS DA TERAPIA COMBINADA DE LOSARTANA COM HIDROCLOROTIAZIDA EM PACIENTES DO PROGRAMA FARMÁCIA POPULAR
}

\author{
Jorge Jonathan de Lima Costa ${ }^{1}$ \\ Thiago Pereira de Abreu
}

\begin{abstract}
RESUMO: Doenças hipertensivas e cardiovasculares constituem-se num importante problema de saúde pública e está entre as principais causas de morte da população adulta nos países desenvolvidos. Evidências clínicas comprovam a importância da hipertensão arterial sistêmica (HAS) como fator de risco. O Programa Farmácia Popular é uma inciativa do Ministério da Saúde e foi criado em 2004 e modificada com parceria de farmácias e Drogarias privadas em 2017. Surgiu como uma alternativa de acesso da população aos medicamentos considerados essenciais para saúde publica. Considerando-se a elevada prevalência de quadros de hipertensão arterial na população e a eficácia da terapêutica medicamentosa no tratamento, o presente estudo buscou comparar a resposta terapêutica relacionada à administração associada destes dois medicamentos Losartana potássica e Hidroclorotiazida na hipertensão, no tratamento de pacientes.
\end{abstract}

Palavras-Chave: Hipertensão. Losartana. Hidroclorotiazida. Farmacêutico. Atenção farmacêutica. Farmácia Popular.

ABSTRACT: Hypertensive and cardiovascular diseases constitute an important public health problem and are among the main causes of death in the adult population in developed countries. Clinical evidence supports the importance of systemic arterial hypertension (SAH) as a risk factor. The Popular Pharmacy Program is an initiative of the Ministry of Health and was created in 2004 and modified in partnership with private pharmacies and drugstores in 2017. It emerged as an alternative for the population to access medicines considered essential for public health. Considering the high prevalence of hypertension in the population and the efficacy of drug therapy in the treatment, the present study sought to compare the therapeutic response related to the combined administration of these two drugs Losartan potassium and Hydrochlorothiazide in hypertension, in the treatment of patients.

KEYWORDS: Hypertension. Losartan. Hydrochlorothiazide. Pharmacist .Pharmaceutical care. Popular Pharmacy.

\footnotetext{
${ }^{\mathrm{I}}$ Universidade Iguaçu. E-mail: jorgejonathanı998@gmail.com.

${ }^{2}$ Orientador. Universidade Iguaçu.
} 


\section{INTRODUÇÃO}

As doenças cardiovasculares constituem-se num importante problema de saúde pública e a principal causa de morte da população adulta dos países desenvolvidos. Evidências clínicas comprovam a importância da hipertensão arterial sistêmica (HAS) como fator de risco (VERONEZ \& SIMÕES, 2008). Mais pessoas morrem anualmente por essas enfermidades do que por qualquer outra causa, Consiste numa doença multifatorial e seu tratamento requer o apoio de outros profissionais de saúde, além do médico, como por exemplo, o profissional farmacêutico prestando a atenção farmacêutica ao paciente, e tornando essencial a formação de uma equipe multiprofissional, possibilitando essa ação diferenciada (BARBOSA et al., 2008).

Estima-se que cerca de $15 \%$ a $20 \%$ na população adulta e mais de $50 \%$ dos idosos apresentam quadro de hipertensão arterial, que por sua elevada prevalência, representa um grave problema de saúde pública e um importante fator de risco para as doenças cardiovasculares responsáveis por cerca de 30\% das mortes (STRELEC et al., 2003).

No controle da pressão arterial, o tratamento com medicamentos costuma ser bem eficaz e diminuiu significativamente os casos de acides de hipertensão e acidente vascular cerebral (RIBAS \& GUIMARÃES, 2006). Mas segundo VERONEZ \& SIMÕES (2008) O tratamento com medicamentos deve começar apenas quando não forem mais suficientes as alternativas das terapias não farmacológicas, como estratégias alimentares, restrição ao fumo, redução de bebidas alcoólicas, redução de peso, realização de atividades físicas e de relaxamento.

O programa Farmácia Popular foi criado em 2004 pelo Ministério da Saúde, e em 2017 passou a contar com parceria de farmácias e rogarias privadas, surgiu como mais uma opção da população ter acesso aos medicamentos considerados essenciais para a saúde.

Nos dias de hoje, o programa Farmácia Popular funciona apenas em farmácias e drogarias privadas e credenciadas pelo governo onde são oferecidos medicamentos gratuitos para hipertensão (pressão alta), diabetes e asma, além de medicamentos com até $90 \%$ de desconto indicados para dislipidemia (colesterol alto), rinite, Parkinson, osteoporose e glaucoma. Ainda pelo sistema de copagamento, o Farmácia Popular oferece anticoncepcionais e fraldas geriátricas.

De acordo com orientações do CNS, há provas que o programa reduziu o numero de internações e óbitos significativamente em casos de hipertensão e diabetes. Conforme a pesquisa do Instituto de Pesquisa Econômica Aplicada (Ipea), 
os municípios que participam do programa diminuíram, em media, 64 internações por complicações de asma, diabetes e hipertensão por roo mil habitantes, quando comparados a municípios não cobertos, no período de 2004 a 2016.

A Losartana potássica, pertencente à família dos bloqueadores dos receptores de angiostensina II, correspondem à segunda classe de drogas anti-hipertensivas, e mais recentemente aprovadas, que agem interrompendo o sistema $\mathrm{da}$ reninaangiostensina, através do bloqueio seletivo do receptor de angiostensina II do tipo I (AT) (OPARIL et. al., 200I). O sistema renina-angiostensina-aldosterona (SRAA) desempenha importante função na regulação da pressão arterial e da homeostase eletrolítica. Os agentes que bloqueiam o SRAA (inibidores da Enzima Conversora de Angiostensina - ECA ou antagonistas de angiotensina II) têm sido empregados em outras condições, tais como insuficiência cardíaca, infarto agudo do miocárdio, nefropatia diabética e disfunção ventricular esquerda (RIBEIRO \& FLORÊNCIO, 2000).

Os diuréticos tiazídicos foram os primeiros anti-hipertensivos disponíveis para uso em larga escala. Lançados em meados dos anos 50 continuam a ser administrados, isolados ou em associação, a milhões de hipertensos em todo o mundo. Foi com esta classe de drogas que se demonstrou redução da morbimortalidade com o tratamento anti-hipertensivo.

\section{- DESENVOLVIMENTO}

\section{I Losartana Potássica}

O sistema renina-angiotensina tem um papel importante no tratamento da hipertensão arterial humana. Em resposta à diminuição do volume sanguíneo efetivo, a renina é liberada pelo aparelho justaglomerular (nos rins). No sangue, a renina é responsável pela conversão do angiotensinogênio (liberado pelo fígado) em angiotensina I e esta, por sua vez, ao entrar em contato com uma enzima denominada Enzima Conversora da Angiotensina (ECA) é convertida em angiotensina II.

Para exercer sua atividade biológica, a angiotensina II liga-se, preferencialmente, ao receptor de alta afinidade ATı estimulando o córtex adrenal a sintetizar e secretar aldosterona e, com isso, diminuir a excreção de sódio, aumentar a excreção de potássio e, consequentemente, fazendo com que a pressão arterial aumente. (RANG et al, 2007; CASSIS, 2008). A losartana potássica (Figura I) é um antagonista ao receptor ATI da angiotensina II e liga-se de forma seletiva e competitiva a este receptor, bloqueando a ligação da angiotensina II e, consequentemente, neutralizando os efeitos da aldosterona. (MAGALHÃES, 2006). 
Segundo auditoria da IMS Health, em 2014, a losartana potássica foi o medicamento mais vendido no Brasil, com vendas que ultrapassaram $\mathrm{R} \$ 515$ milhões de reais (CFF, 2015).

FIGURA r. Fórmula estrutural da losartana potássica. (DRUG BANK, 2018)

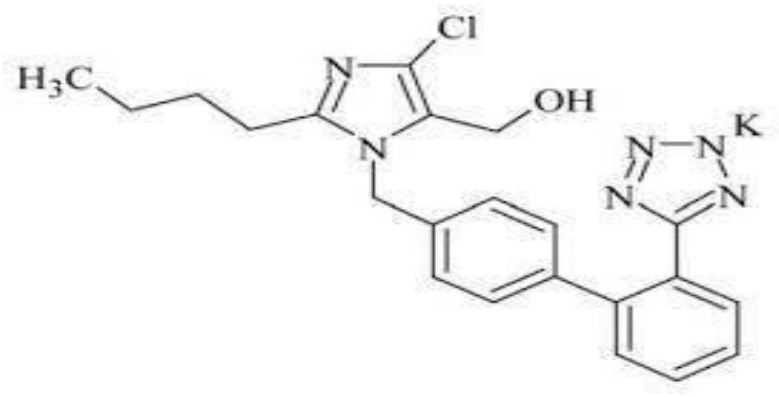

\section{2- Propriedades Físico-Química Da Losartana Potássica}

A losartana potássica possui fórmula molecular $\mathrm{C}_{22} \mathrm{H}_{22} \mathrm{ClKN6O}$ e é denominada pela IUPAC como 2-Butyl-4-chloro-I-\{[2'-(IH-tetrazol-5-yl)(I,I'biphenyl)-4-yl]methyl\}-IH-imidazole-5-methanol monopotassium salt. Possui aparência de um pó fino, de coloração branca, com ponto de fusão entre $263-265^{\circ} \mathrm{C} \mathrm{P}$ á g i n a 27 e massa molar de 46ı,oor g mol-ı. Seu logP (octanol/água) previsto é de 4,48 e seu pKa é de 4,15 (DRUG BANK, 2018), caracterizando-se como um ácido fraco.

Em pacientes tratados com diuréticos, recomenda-se iniciar com dose de 50 $\mathrm{mg}$ de Losartana. A dose inicial para pacientes com insuficiência cardíaca é de 12,5mg uma vez ao dia. A Losartana Potássica é um antagonista do receptor (tipo ATI) da angiotensina II. Liga-se seletivamente ao receptor ATI. Tanto a losartana quanto seu metabólito ácido carboxílico farmacologicamente ativo (E-3174) bloqueiam todas as ações fisiologicamente relevantes da angiotensina II, sem levar em consideração sua fonte ou via de síntese (FARIA et al., 2002). Além disso, a Losartana Potássica não inibe a ECA (cininase II), a enzima que degrada a bradicinina.A Losartana pode ser encontrada na foma de 25 , 50 e roo $\mathrm{mg}$. Em adultos a dose inicial normalmente é de $50 \mathrm{mg}$ duas vezes ao dia.Segundo MINISTÉRIO DA SAÚDE, ANVISA no Bulário de 2012; geralmente, a dose deve ser titulada em intervalos semanais (isto é, I2,5mg, $25 \mathrm{mg}$, 5omg, uma vez ao dia) de acordo com a tolerabilidade do paciente.

Segundo FARIA et al., 2002; os efeitos não relacionados diretamente ao bloqueio do receptor $\mathrm{AT}$, como a potencialização dos efeitos mediados pela bradicinina ou o desenvolvimento de edema, não estão associados .A principal ação da angiotensina II está no controle da pressão arterial. Este hormônio, liga-se as paredes dos vasos e faz com que estes se contraiam, provocando assim um aumento 
da pressão arterial. Segundo RIBEIRO \& FLORÊNCIO, 20oo;A angiotensina II também age nos rins, estimulando uma maior absorção de sódio, o que também acaba por colaborar para o aumento da pressão arterial. Como foi observado, o

Hidrocloridiazida e a Losartana são classes diferentes de drogas, porém, com mecanismo de redução da pressão arterial diferente. Ambos têm como objetivo impedir a ação de um hormônio chamado angiotensina II. A Losartana impede o seu funcionamento através de antagonismo, uma vez que compete pelo mesmo receptor ATı com a angiotensina. Em relação aos efeitos de proteção cardíaca e renal os medicamentos se equivalem. Já no quesito efeitos colaterais há algumas diferenças, uma vez que a Losartana Potássica é antagonista da ECA, não impedindo, assim, totalmente sua função.

\section{3- Farmacocinética}

Após a administração oral, a losartana é bem absorvida e sofre metabolismo de primeira passagem, formando um metabólito ativo do ácido carboxílico e outros metabólitos inativos. A biodisponibilidade sistêmica dos comprimidos de losartana é de aproximadamente $33 \%$.

As médias das concentrações máximas de losartana e de seu metabólito ativo são atingidas em I hora e em 3-4 horas, respectivamente. Não houve efeito clinicamente significativo sobre o perfil de concentração plasmática da losartana quando o fármaco foi administrado com uma refeição padrão.

\section{2- Hidroclorotiazida}

A hidroclorotiazida é um diurético tiazídico usado principalmente na hipertensão arterial. A hidroclorotiazida pertence ao grupo dos saluréticos e atua no tubulo distal do nefron a nível do cotransportador sensível das tiazidas (TSC) que é um canal de suporte $\mathrm{Na}+/ \mathrm{Cl}$-. Deste modo há uma maior excreção de $\mathrm{NaCl}$ e de água (por efeito osmótico). Esta perda de água aumenta a diurese e diminuí o volume líquido extracelular e consequentemente baixo a pressão sanguínea.

A eficácia e a segurança de hidroclorotiazida foram comprovada com propriedade por Frishman W.H. et al. em seu estudo comparativo placebo controlado, envolvendo 207 pacientes portadores de hipertensão arterial leve para moderada, que foram acompanhados por 26 semanas, comprovou-se uma grande diminuição da pressão com hidroclorotiazida. Kumar E.B. et al. comprovou em seu estudo com 24 pacientes usando hidroclorotiazida por 30 dias, que uma única dose de hidroclorotiazida é eficaz na diminuição da pressão arterial. Vardan S. et al. também comprovou a eficácia e segurança de hidroclorotiazida, envolvendo 24 pacientes com 
hipertensão arterial usando a hidroclorotiazida por I mês, diminuindo os elevados níveis de hipertensão arterial dos pacientes envolvidos no estudo. Bope et al. em seu estudo randomizado envolvendo 157 pacientes acompanhados por 12 semanas, utilizando hidroclorotiazida diariamente, pode comprovar que hidroclotiazida diminuiu a pressão arterial sistólica e diastólica. Reyes AJ. em sua publicação, uma meta-análise sobre monoterapias diuréticas em pacientes hipertensos, comprovou a eficácia monoterápica de diuréticos na diminuição de hipertensão arterial.

\section{1- Propriedades Físico-Química Da Hidroclorotiazida}

Fórmula molecular $\mathrm{C}_{7} \mathrm{H}_{8} \mathrm{~N}_{3} \mathrm{ClO}_{4} \mathrm{~S}_{2}$. Massa molar 297,74I $\mathrm{g} / \mathrm{mol}$. Nomenclatura IUPAC (sistemática) 9-cloro-5,5-dioxo-5^6-tia-2,4diazabiciclo[4.4.0]deca-6,8, Io-triene-8-sulfonamida. Palavras-chave: Hidroclorotiazida. Medicamentos. Química orgânica. Doping.

Figura 2. Fórmula estrutural da Hidroclorodiazida .<smiles>NS(=O)c1cc2c(cc1Cl)NCNS2=O</smiles>

\section{2- Farmacocinética Da Hidroclorotiazida}

A hidroclorotiazida é rapidamente absorvida pelo trato gastrointestinal. O efeito diurético começa dentro de cerca de 2 horas, o efeito máximo é alcançado após cerca de 4 horas e dura cerca de 6 - 12 horas.

É excretada inalterada na urina. A meia-vida é de 6 a 15 horas. Os níveis plasmáticos persistem por pelo menos 24 horas. A hidroclorotiazida não é metabolizada, mas é rapidamente excretada pelos rins. Pelo menos 61\% de uma dose oral é excretada inalterada na urina em 24 horas. A hidroclorotiazida atravessa a barreira placentária e é excretada no leite materno.

\section{3- INTERAÇÃO LOSARTANA-HIDROCLOROTIAZIDA}

Quando utilizadas em combinação, a losartana e a hidroclorotiazida apresentam efeito aditivo quanto a sua eficácia anti-hipertensiva. $O$ efeito anti-hipertensivo de Losartana Potássica e Hidroclorotiazida é mantido por um período de 24 horas. 
Os componentes de Losartana Potássica com Hidroclorotiazida apresentam efeito aditivo sobre a redução da pressão arterial, diminuindo a pressão arterial a um grau maior do que qualquer um dos componentes isoladamente. Acredita-se que esse efeito seja resultado de ações complementares de ambos os componentes. Além disso, como resultado de seu efeito diurético, a hidroclorotiazida aumenta a atividade plasmática de renina, a secreção de aldosterona e os níveis de angiotensina II e diminui o potássio sérico.

A administração de losartana bloqueia todas as ações fisiologicamente relevantes da angiotensina II e, por meio da inibição da aldosterona, poderia tender a atenuar a perda de potássio associada ao diurético.

A losartana apresenta efeito uricosúrico leve e transitório. A hidroclorotiazida causa aumentos modestos do ácido úrico; a combinação de losartana e hidroclorotiazida tende a atenuar a hiperuricemia induzida pelo diurético.

A hidroclorotiazida deste medicamento faz com que os rins eliminem mais sal e água. Juntos, a losartana e a hidroclorotiazida reduzem a pressão alta. Embora seu médico possa lhe dizer se o medicamento está agindo por meio da medida da sua pressão arterial, provavelmente você não notará diferenças ao tomar losartana potássica + hidroclorotiazida.

\section{CONCLUSÃO}

Neste trabalho buscamos descrever as interações e a prescrição de Losartana e Hidrocloridiazida prescritos que utilizam o Programa Farmácia Popular. Para analisarmos seu funcionamento, sua abrangência e sua relação existente com pacientes de interação do SUS.

Após revisão de referencial teórico, na qual discorremos sobre leituras e revisões bibliográficas, sobre a regularidade do uso concomitante desses medicamentos e sobre eficácia em pacientes escrito no Programa Farmácia Popular do Brasil.

A prescrição médica correta é uma conduta de grande importância para auxiliar não obtenção de resultados positivos com a farmacoterapia, além de contribuir para o uso racional de medicamentos. A Farmácia Popular do Brasil com a implantação da nova forma de dispensação vem colaborar para que o usuário tenha uma dispensação de qualidade. Devido à identificação das situações de risco para o uso de medicamentos, interações medicamentosas e contra indicações, foram realizadas condutas referentes à orientação aos pacientes levando a melhora na utilização dos medicamentos e o sucesso terapêutico. 
Compõem o elenco de medicamentos gratuitos para hipertensão, do Programa Farmácia Popular do Brasil a hidroclorotiazida 25 mg e losartana 50 mg.(MS, 2012)

Não foi encontrada citações de interação farmacológica entre os diuréticos tiazídicos (hidroclorotiazida) e os antagonistas de receptores da angiotensina II (losartana). Por outro lado, existem inúmeras evidências do efeito sinérgico do uso concomitante ou associação de baixas doses desses diuréticos com os antagonistas de receptores da angiotensina II, para controle da hipertensão arterial.(Aronson, 2006)

Hidroclorotiazida, protótipo dos diuréticos tiazídicos, é indicada, em baixas doses orais, como primeira escolha no tratamento de hipertensão arterial sistêmica. É usado como adjuvante no tratamento de insuficiência cardíaca crônica controlada, tendo a vantagem de efeito diurético moderado e possibilidade de uma administração diária. Pode também ser empregada em hipercalciúria e em diabetes não insulino dependente (diabetes tipo II).(FTN, 2010)

De acordo com FTN 2oı́, a hidroclorotiazida deve ser usada com precaução nos casos de:

- Uso de altas doses do fármaco ou em insuficiência renal (monitorar nível sérico dos eletrólitos).

- Diabete insulino dependente (diabetes tipo I), porfiria, hipotensão, lúpus sistêmicos, gota, hiperaldosteronismo, síndrome nefrótica. -Insuficiência renal. - Idosos (usar a menor dose efetiva, especialmente nos que apresentam alterações eletrocardiográficas).

- Lactação.

Os efeitos adversos das tiazidas sobre o metabolismo da glicose, tais como a resistência à insulina, diminuição da tolerância à glicose, a precipitação de diabetes evidente, e agravamento de controle diabético, são bem estabelecidas, mas parecem estar relacionadas com a dose e pode não ser significativa em doses mais baixas (por exemplo, hidroclorotiazida 6,25 ou 12,5 mg).(Klasco, 2012)

A losartana atenua ligeiramente as respostas hormonais e sintomáticas da hipoglicemia, reduzindo a percepção do paciente. Por isso, deve ser empregada com cuidado em pacientes diabéticos. (Klasco, 2012)

Assim, se este paciente específico fizer uso de algum fármaco para controle hipoglicêmico, o risco-benefício deverá ser considerado.

O Programa Farmácia Popular tem algumas restrições quanto à quantidade mensal de comprimidos liberados, ao uso concomitante de medicamentos para 
controle de hipertensão arterial, em situações mudança do tratamento farmacológico e outros, que podem estar interferindo no atendimento deste paciente.

\section{REFERÊNCIA}

ARONSON JK, DUKES MNG(ED.). MEYLER'S SIDE EFFECTS OF DRUGS. I5 ed. Amsterdam: elsevier, 2006.p 3378

BARBOSA RG, LIMA NK. Indices De Adesão Ao Tratamento Anti-Hipertensivo No Brasil E Mundo. Ver Bras Hipertens. 2006; (I):35-8

Blessy, m.; patel, r. D.; prajapati. P. N.; agrawal, y. K. Development of forced degradation and stability indicating studies of drugs - a review. J. Pharm. Anal, v. 4, n. 3, p. 159-165, 2014.

Brasil. Ministério da saúde. Portal da saúde. Disponível em: http://portal.saude.gov.br/portal/saude/area.cfm?id_area=I095 acesso em 17.07.2012

BRASIL, MINISTÉRIO DA SAUDE. Relação Nacional de Medicamentos Essenciais- Remane, Série B. Textos Básicos de Saúde, $6^{\circ}$ edição , Brasília - DF, 2008.

CANO, . M. P. Atenção farmacêutica e Hipertensão. Revista Racine, v. 88, Setembro/Outubro, 2005.

CÉSAR, L. A. M. Sistema renina-angiotesina-aldosterona e doenças isquêmicas, Revista Brasileira de Hipertensão, v 3, p. 225-26o, 2000.

CFF - CONSELHO FEDERAL DE FARMÁCIA (2015). Curtas: O Medicamento Mais Vendido Do Brasil Em 2014. Disponível Em: Acesso Em 9 De Março De 2018.

CONTINERO AP, POZATI MP, CHALLOUTS RI, CARREIRA L, MARCON DD.IDOSO Com Hipertensão Arterial; Dificuldades De Acompanhamento Na Estratégia Saúde Da Familia. Rev Gaucha Enferm. 2009; 30 ();62-70 
DRUG BANK. Disponível em: . Acesso em 9 de março de 2018.

FRISHMAN WH, ET Al. Comparison Of Hydrochlorothiazide And SustainedRelease Diltiazem For Mild-To- Moderate Systemic Hypertension. Am J Cardiol. 1987 Mar;59(6):615-23.

KLASCO RK (ED): Martindale: The Complete Drug Reference. Thomson Micromedex, Greenwood Village, Colorado, Usa. Disponível Em: Http://Www.Thomsonhc.Com/. Acesso Em: 17.07.2012.

KUMAR EB, ET AL. Circulatory Dose-Response Effects Of Hydrochlorothiazide At Rest And During Dynamic Exercise In Essential Hypertension. J R Coll Physicians Lond. 1982 Oct;16(4):232-5.

MAGAlHÃES, L.B.N.C. Anti-Hipertensivos. In: Silva, P. Farmacologia. 7 Ed. Rio De Janeiro: Guanabara Koogan, 20o6. Cap. 68. 